\title{
The Effects of Maternal Metformin Treatment on Late Prenatal and Early Postnatal Development of the Offspring Are Modulated by Sex
}

\author{
Consolacion Garcia-Contreras ${ }^{1}$, Marta Vazquez-Gomez ${ }^{2,3}{ }^{\circledR}$, José Luis Pesantez-Pacheco ${ }^{1,4}$ (i), \\ Ana Heras-Molina ${ }^{1}$ (D), Teresa Encinas ${ }^{2}$, Susana Astiz ${ }^{1(D)}$ and Antonio Gonzalez-Bulnes ${ }^{1,2, *(D)}$ \\ 1 SGIT-INIA, Ctra. De La Coruña Km. 7,5, 29040 Madrid, Spain; congarcon@gmail.com (C.G.-C.); \\ jose.pesantez@ucuenca.edu.ec (J.L.P.-P.); delasheras.ana@inia.es (A.H.-M.); astiz.susana@inia.es (S.A.) \\ 2 Faculty of Veterinary Medicine, UCM, Ciudad Universitaria s/n., 28040 Madrid, Spain; \\ martavazgomez@gmail.com (M.V.-G.); tencinas@vet.ucm.es (T.E.) \\ 3 Facultat de Veterinària, Universitat Autònoma de Barcelona. Edifici V, Trav. dels Turons, \\ 08193 Bellaterra, Spain \\ 4 Faculty of Agricultural Sciences, School of Veterinary Medicine and Zootechnics, University of Cuenca, \\ Avda. Doce de Octubre, 010220 Cuenca, Ecuador \\ * Correspondence: bulnes@inia.es; Tel.: +34-91-347-4022
}

Received: 13 October 2020; Accepted: 3 November 2020; Published: 4 November 2020

\begin{abstract}
Metformin is currently used to improve pregnancy outcome in women affected by polycystic ovary syndrome (PCOS) or diabetes. However, metformin may also be useful in pregnancies at risk of intrauterine growth restriction (IUGR) since it improves placental efficiency and the fetuses' developmental competence. There is no data on the duration of the effect of this treatment from the prenatal up to the postnatal stages. Therefore, the present trial aimed at determining the impact of metformin treatment on the offspring neonatal traits and early postnatal development (i.e., during lactation) using an in vivo swine model. The results support that maternal metformin treatment during pregnancy induces protective changes in body shape and composition of the progeny (i.e., larger head size and body length at birth and higher total viscera weight at weaning). However, there were also major effects of the offspring sex (smaller corpulence in females and lower relative weight of main viscerae in males), which should be considered for further preclinical studies and when even the current clinical application in women affected by PCOS or diabetes is implemented.
\end{abstract}

Keywords: intrauterine growth restriction; metformin; pregnancy; swine model

\section{Introduction}

Intrauterine growth restriction (IUGR), the failure of a fetus to reach its full genetic growth potential, affects between $6 \%$ and $17 \%$ of total human pregnancies; a range depending on environmental and socioeconomic factors. IUGR results in small-for-gestational-age (SGA or low-birth-weight, LBW) offspring, with SGA being the second leading cause of infant mortality and morbidity after premature birth. IUGR directly affects the life-quality and well-being of many individuals and causes a huge financial burden to the public health care systems [1].

In consequence, IUGR has been the focus of intense research during the last 40 years, but mainly during the last ten years [2] as the traditional causes for IUGR (maternal malnutrition and hypoxia in developing areas and extreme environments) are reinforced by a contemporary increase in the incidence of "placental insufficiency" in both developing and developed countries [3]. The term "placental insufficiency" defines a deficiency in the placental development and function, causing a shortage of the transfer of nutrients and oxygen to the fetus. This condition is currently estimated to 
be the cause of around $60 \%$ of IUGR cases [4]. Moreover, placental insufficiency is a rising problem, since it is linked to many contemporary factors (delay in childbearing age, inadequate lifestyle, stress, sedentarism, pollution, alcohol and tobacco intake, obesity, diabetes or preeclampsia [5]).

The current magnitude and the expected future increment of IUGR incidence make necessary to increase the research on diagnostic, preventive, and therapeutic approaches. Preventive and therapeutic strategies are mainly based, to date, on lifestyle and diet changes, since there are no therapeutic actions with proven validity and the final solution is the induction of a preterm delivery. In fact, around $40 \%$ of premature births, which are the leading cause for infant mortality and morbidity, is related to the medical indication to induce birth before the 34th week of gestation, due to IUGR [6]. Therefore, research for therapeutic tools focuses on the improvement of placental development and functionality by either pharmacological treatments (e.g., aspirin or sildenafil citrate) or nutritional supplementation (e.g., amino acids, vitamins favoring protein synthesis or antioxidant status, and other antioxidants such as polyphenols). Such research cannot be carried out in human beings, so the use of animal models (either rodents or large animals) is unavoidable [7].

Our group has approached, using a well-proven swine IUGR model [8,9], a distinctive pharmacologic alternative: the use of metformin. Metformin is a drug widely used for the treatment and prevention of diabetes [10], and it is currently tested to prevent large-for-gestational-age (LGA) offspring in pregnant mothers with diabetes [11,12], the opposite scenario to IUGR and SGA offspring. However, metformin favors the transfer and uptake of glucose to peripheral tissues [13] without inducing maternal hypoglycemia [14]. Our hypothesis was that metformin treatment in IUGR compromised pregnancies might favor the uptake of glucose by the placenta and fetus and, consequently, improve fetal development. We found that the maternal treatment with metformin, despite no significant effects on fetal body mass, favored placental development and fetal viscera growth (mainly brain, liver, kidneys, spleen, and adrenal glands) [15]. These organs are pivotal for the survival and development of the newborns, with these findings suggesting a beneficial effect of the metformin treatment on the fetuses' developmental competence and, afterwards, neonates.

These results are of high value for human medicine in case of maternal malnutrition, frequent in developing areas. Metformin is a cheap drug easily available which seems to improve placental development, in case of placental deficiency. However, there are no data on the duration of these effects up to postnatal stages of the offspring or on the safety use of the drug during pregnancy [16]. Thus, the present trial aimed at determining the effects of the maternal metformin therapy on neonatal traits and early postnatal development (i.e.: during lactation) of the offspring in mammals.

\section{Results}

\subsection{Effects of Maternal Metformin Treatment on Late Prenatal Development and Neonatal Features}

The mean litter size was similar in both control and metformin-treated groups $(7.8 \pm 0.6$ piglets/litter in the Group Control, Group C, and $8.0 \pm 0.7$ piglets/litter in the treated group, Group METF). The sex ratio of piglets was close to 1:1 in both groups, with 21 female and 26 male piglets in group C $(44.7 \%$ and $55.3 \%$, respectively) and 38 female and 34 male piglets in the group METF $(52.7 \%$ and $47.3 \%$, respectively).

There was no disparity in the mean birthweight between piglets between the groups (Table 1), but there were significant birth-size differences. Piglets in the group METF, independently of sex, showed a larger head size (in terms of higher values for both occipito-nasal length and biparietal diameter; $p<0.0005$ and $p<0.005$, respectively, with a higher ratio occipito-nasal to length/biparietal diameter; $p<0.05)$ and a longer body length $(p<0.05)$. Conversely, differences in corpulence were determined by an interaction sex*treatment. In this sense, METF males had similar thoracic and abdominal circumferences to those from control males, while female piglets in the group METF showed smaller thoracic and abdominal circumferences than $C$ females $(p<0.005$ and $p<0.05$, respectively). A within-group comparison showed that body weight and size were similar between females and 
males in the group $C$ (excepting a trend for lower body length in males, $p=0.06$ ). Males in the group METF showed a trend for a higher body weight $(p=0.06)$ and higher values for occipito-nasal length and thoracic circumference ( $p<0.05$ for both) than their female littermates.

Table 1. Mean ( \pm SEM) values for birthweight and size in newborn piglets from controls (group C) and sows treated with metformin during pregnancy (group METF).

\begin{tabular}{ccccc}
\hline \multirow{2}{*}{ Parameter } & \multicolumn{2}{c}{ Group C } & \multicolumn{2}{c}{ Group METF } \\
\cline { 2 - 5 } & Females & Males & Females & Males \\
\hline Body weight $(\mathrm{g})$ & $1.13 \pm 0.03$ & $1.15 \pm 0.03$ & $1.11 \pm 0.03$ & $1.16 \pm 0.03$ \\
Body length $(\mathrm{cm})$ & $23.27 \pm 0.34^{\mathrm{a}}$ & $23.03 \pm 0.28^{\mathrm{e}}$ & $23.72 \pm 0.30^{\mathrm{b}}$ & $23.92 \pm 0.29^{\mathrm{f}}$ \\
Occipito-nasal length $(\mathrm{cm})$ & $11.14 \pm 0.22^{\mathrm{e}}$ & $11.31 \pm 0.19^{\mathrm{e}}$ & $11.93 \pm 0.13^{\mathrm{f}, 1}$ & $12.27 \pm 0.16^{\mathrm{f}, 2}$ \\
Biparietal diameter $(\mathrm{cm})$ & $4.57 \pm 0.08^{\mathrm{a}}$ & $4.58 \pm 0.07^{\mathrm{a}}$ & $4.77 \pm 0.05^{\mathrm{b}}$ & $4.77 \pm 0.07^{\mathrm{b}}$ \\
Thoracic circumference $(\mathrm{cm})$ & $23.25 \pm 0.29^{\mathrm{c}}$ & $22.48 \pm 0.29$ & $22.20 \pm 0.19^{\mathrm{d}, 1}$ & $22.64 \pm 0.27^{2}$ \\
Abdominal circumference $(\mathrm{cm})$ & $18.76 \pm 0.31^{\mathrm{a}}$ & $18.63 \pm 0.30$ & $17.83 \pm 0.23^{\mathrm{b}}$ & $18.28 \pm 0.30$ \\
\hline
\end{tabular}

Superscripts denote significant differences between treatments $(\mathrm{a} \neq \mathrm{b}: p<0.05 ; \mathrm{c} \neq \mathrm{d}: p<0.005 ; \mathrm{e} \neq \mathrm{f}: p<0.0005)$ and between sexes within treatments $(1 \neq 2: p<0.05)$.

\subsection{Effects of Maternal Metformin Treatment on Early Postnatal Development and Body Composition}

The growth of the piglets during the suckling period was similar in both groups, without any difference in average daily weight gain (ADWG) and fractional growth rate (FGR), and therefore in body weight, during this stage (Figure 1).
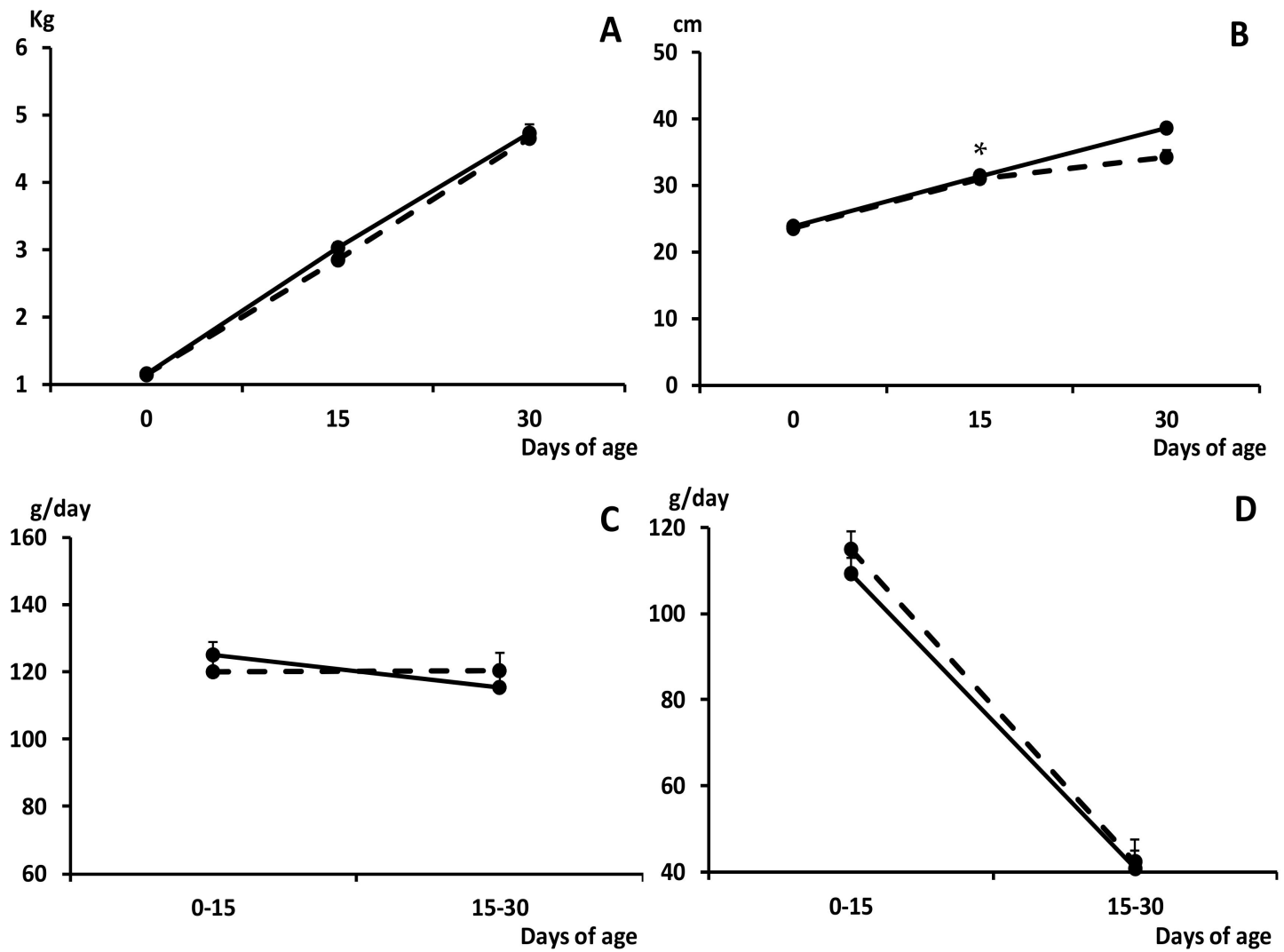

Figure 1. Change over time in mean values ( \pm S.E.M.) of body weight and length (panels (A) and (B), respectively), average daily weight gain (ADWG; panel (C)) and fractional growth rate (FGR; panel (D)), during the early postnatal development ( 0 to 30 days old) in piglets from control (group C; black dots with discontinuous lines) and sows treated with metformin during pregnancy (group METF; black dots with continuous line). Asterisk denotes significant differences between groups $\left({ }^{*} p<0.05\right)$. 
The higher values for occipito-nasal length and biparietal diameter found at birth in METF piglets than in $C$ counterparts remained at 15 days old ( $p<0.05$ for both; Figure 2). Female piglets in the group METF continued showing smaller thoracic and abdominal circumferences than $C$ females at the age of both 15 ( $p=0.06$ and $p<0.0005$, respectively) and 30 days ( $p<0.05$ and $p<0.0005$, respectively). Smaller thoracic and abdominal circumferences in METF males than in $\mathrm{C}$ males were also found at 30 days old $(p<0.0005$ and $p<0.005$, respectively).
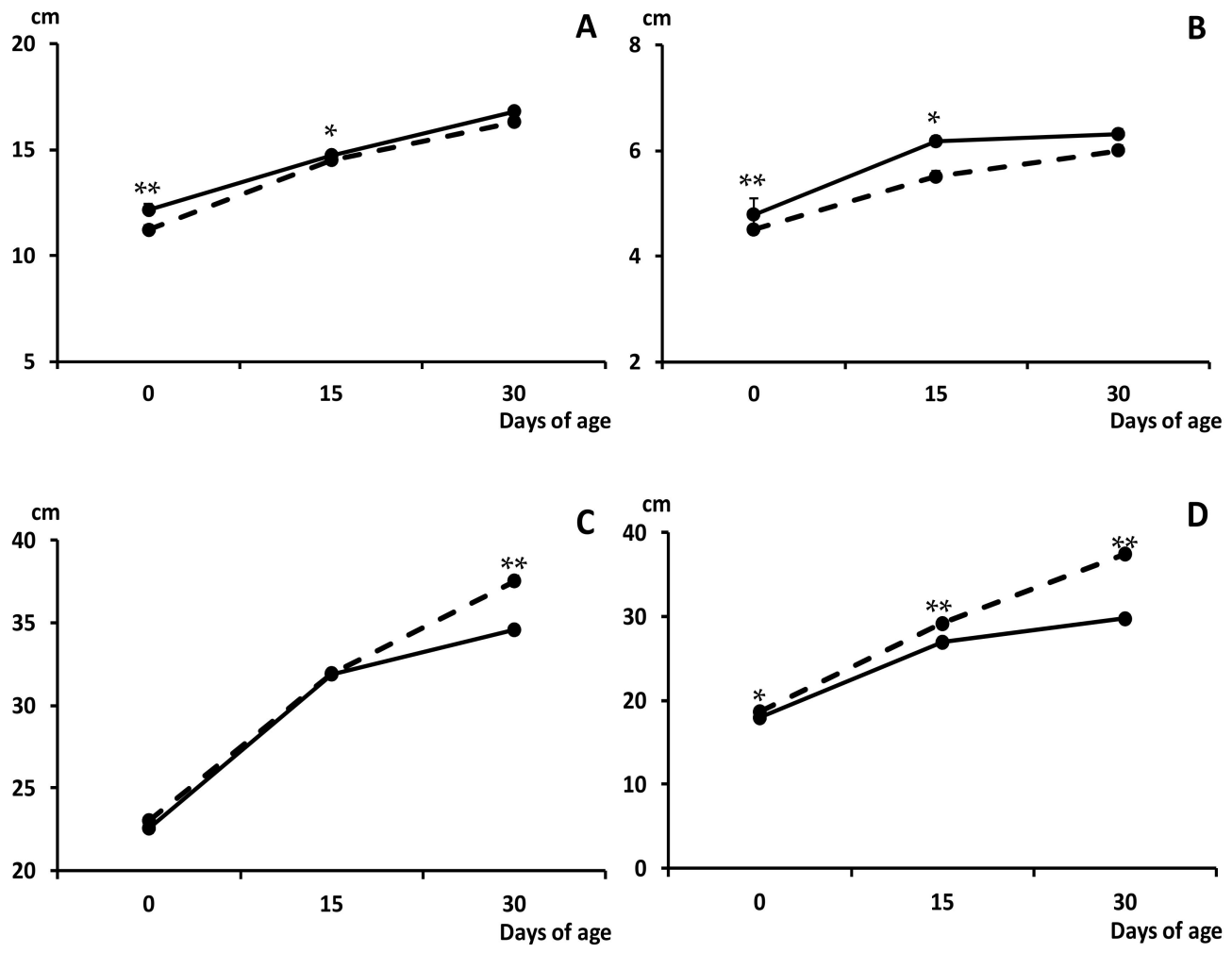

Figure 2. Change over time in mean values ( \pm S.E.M.) of the occipito-nasal length (panel (A)), biparietal diameter (panel (B)) and thoracic and abdominal circumferences (panels (C) and (D), respectively) during the early postnatal development ( 0 to 30 days old) in piglets from control (group C; black dots with discontinuous lines) and sows treated with metformin during pregnancy (group METF; black dots with continuous line). Asterisks denote significant differences between groups $\left({ }^{*} p<0.05 ;{ }^{* *} p<0.01\right)$.

On the other hand, at weaning, METF piglets showed a higher muscle development, as determined by assessing the loin diameter (11.4 \pm 0.02 vs. $9.8 \pm 0.021 \mathrm{~mm}$ for group $C ; p<0.0005)$, and subcutaneous fat accumulation, as determined by evaluating the back-fat depth $(5.1 \pm 0.01 \mathrm{vs} .4 .0 \pm 0.01 \mathrm{~mm}$ for group $C ; p<0.0005)$. These differences were independent of sex.

At weaning, there were no significant differences between groups $C$ and METF in the absolute body weight or in the absolute weight of head, carcass, and viscerae (Table 2), excepting a significant lower weight of the kidney in METF males. However, there was a trend for a higher absolute weight of total viscerae in the group METF, which resulted in a higher relative viscerae-to-body weight ratio than in the group $C$ ( $p=0.06$ and $p<0.0005$, respectively). The comparison of these traits between males and females within groups showed no differences in METF piglets, but the females of the group $C$ showed a lower relative weight of the carcass and a higher relative weight of viscerae than their male group C counterparts ( $p<0.01$ and $p<0.05$, respectively). 
Table 2. Mean $( \pm$ SEM) values for absolute weight of different organs and structures at weaning (i.e., 30 days old) in offspring from control (group C) and sows treated with metformin during pregnancy (group METF).

\begin{tabular}{ccccc}
\hline \multirow{2}{*}{ Parameter (g) } & \multicolumn{2}{c}{ Group C } & \multicolumn{2}{c}{ Group METF } \\
\cline { 2 - 5 } & Females & Males & Females & Males \\
\hline Body & $4986.76 \pm 112.65$ & $4895.59 \pm 137.63$ & $4728.75 \pm 74.11$ & $4777.13 \pm 88.72$ \\
Head & $689.67 \pm 9.23$ & $666.71 \pm 12.68$ & $653.42 \pm 10.45$ & $645.22 \pm 6.99$ \\
Carcass & $3053.83 \pm 51.04$ & $3219.43 \pm 98.94$ & $3048.53 \pm 110.45$ & $2955.56 \pm 104.3$ \\
Total viscerae & $835.00 \pm 17.76$ & $755.29 \pm 24.49$ & $895.0 \pm 16.88$ & $849.59 \pm 16.64$ \\
Heart & $32.17 \pm 0.50$ & $30.57 \pm 0.62$ & $35.38 \pm 0.77$ & $35.09 \pm 1.08$ \\
Lungs & $71.67 \pm 1.65$ & $81.14 \pm 3.21$ & $79.66 \pm 1.47$ & $77.44 \pm 1.36$ \\
Liver & $131.00 \pm 1.63$ & $131.86 \pm 3.11$ & $132.10 \pm 2.62$ & $131.56 \pm 2.52$ \\
Intestine & $429.17 \pm 10.80$ & $352.86 \pm 17.31$ & $439.72 \pm 9.70$ & $411.48 \pm 7.88$ \\
Kidneys & $28.33 \pm 0.38$ & $29.71 \pm 0.60$ a & $28.36 \pm 0.47$ & $27.00 \pm 0.43 \mathrm{~b}$ \\
Spleen & $11.42 \pm 0.18$ & $16.39 \pm 0.67$ & $15.45 \pm 0.50$ & $13.95 \pm 0.52$ \\
Pancreas & $4.99 \pm 0.28$ & $6.11 \pm 0.13$ & $5.57 \pm 0.20$ & $5.32 \pm 0.18$ \\
Adrenal glands & $0.71 \pm 0.02$ & $0.95 \pm 0.02$ & $0.85 \pm 0.02$ & $0.88 \pm 0.02$ \\
\hline
\end{tabular}

Superscripts denote significant differences between treatments $(\mathrm{a} \neq \mathrm{b}: p<0.05)$.

These differences in the weight of total viscerae influenced the assessment of the individual relative weights of the different thoracic and abdominal organs (heart, lungs, liver, intestine, kidney, spleen, pancreas, and adrenal glands). In brief, there were no significant differences in the absolute weights of the different viscerae between treatments. There were no sex-related differences within the group METF, but males in group $C$ showed a higher absolute weight of spleen and adrenal glands than their female counterparts ( $p<0.05$ and $p<0.01$, respectively). On the other hand, the analysis of differences in the relative weights of different organs between treatment groups showed determinant sex-related effects. The comparison of the weight of the different organs to total viscera weight showed no significant differences between $C$ and METF females, despite numerically higher values in treated METF females. Conversely, when compared to $C$ males, METF males had lower relative weights of kidneys $(p<0.0005)$, liver, lungs, pancreas, and spleen $(p<0.005$ for all $)$ and adrenal glands $(p<0.05)$ and higher relative weight of the intestine $(p<0.005)$.

\section{Discussion}

The results obtained in the present study evidence that metformin treatment during pregnancy induces a change in body shape and composition of the progeny and address a prominent role of the offspring sex on its response to such therapies.

Maternal metformin treatment during pregnancy did not induce significant differences in birthweight but in body shape, similarly to our previous study performed during the last days of pregnancy [15]. In brief, offspring from metformin-treated pregnancies had significantly higher values for head size (both when assessing occipito-nasal length and biparietal diameter) and body length. These results are highly interesting since recent studies addressed that head profile (size, length and width) and body shape (body length and width) at birth are more predictive of the postnatal development in SGA piglets than the proper birthweight [17,18].

The head profile allows discrimination between piglets that have suffered severe IUGR and piglets that have been less affected and have been born small for gestational age (e.g., proportionally small [19]). In this sense, a dolphin-like forehead (a small and short but wide head) in SGA piglets is clearly indicative of severe IUGR with an adaptive brain sparing effect $[18,20]$. In our study, the head was significantly larger and longer in metformin-treated piglets than in control ones, suggesting an alleviation of IUGR effects. A similar effect was described in human pregnancies affected by polycystic ovarian syndrome (PCOS) and therefore treated with metformin [21,22]. However, there is still unclear the association between metformin and increases in head size and how these changes might affect 
future cognitive and mental traits, since head and brain size are positively related to better cognitive function $[22,23]$. These authors suggest a direct effect on brain development of metformin, which is known to be able to reach the fetus [24,25] and to cross the brain-blood barrier [26], but further specific studies are necessary.

The assessment of the body shape at birth in the present study showed a longer body in the metformin-treated neonates and demonstrated sex-related differences in the response of the offspring to the treatment. In this regard, there were no differences between male counterparts, but metformin-treated females showed a smaller corpulence with smaller thoracic and abdominal circumferences than their female control counterparts. At birth, the abdominal circumference is considered a reliable predictor, with a direct relationship, for the developmental potential during the early postnatal period [17]. Such smaller corpulence of treated females remained during the lactation period and at weaning, but there was also a significant lower corpulence at weaning in the treated males. However, at weaning, traits for muscle development and subcutaneous back fat were higher in both female and male metformin-treated piglets. This is opposite to data on abdominal circumferences since higher values of these traits at weaning prove a good growth in the lactation period and are related to better development, and better yields, during the growing phase [27-29].

A possible hypothesis, considering similar body mass with higher corpulence in controls and better muscle development in metformin-treated piglets, would be a reduction of fattening in these latter individuals. In fact, in pigs, the thoracic circumference is considered mainly predictive for the amount of carcass fat while abdominal circumference is considered mainly predictive of visceral fat [30-32]. The Iberian piglets from food-deprived pregnancies are characterized by a sex-related catch-up growth: females, but no males, have an enhanced growth during lactation [8]. The objective is counteracting IUGR, but such a catch-up growth may be detrimental in case of overnutrition, leading to obesity and associated disorders [33-36]. Accordingly, Iberian female piglets from underfed pregnancies have increased body weight, corpulence, and adiposity at juvenile periods compared to females from pregnancies with adequate nutrition [37,38]. A subsequent study from our group indicated that metformin treatment in these piglets during the juvenile development induces an improvement in body mass by favoring muscle deposition without fattening [39], so similar effects might be expected during prenatal and early postnatal development.

However, these hypotheses should be obviously addressed in future studies; moreover, when a previous study in women with PCOS gave a warning about increased body mass indexes (BMI) in metformin-exposed children [22]. Conversely, evidence found in other clinical studies on pregnant women with diabetes or PCOS indicate similar outputs to those from our study. In brief, children exposed to metformin during pregnancy were larger in size and heavier, but there were no negative effects on the total or abdominal body fat percent or on the metabolic measures [40-43]. Moreover, one of these trials, similarly to ours, demonstrated more subcutaneous fat without increasing overall body fat in metformin-treated individuals during lactation [43].

The assessment of body composition at weaning demonstrated that control females showed a lower relative weight of the carcasses and a higher relative weight of total viscerae than their male littermates. These results support previous findings in our IUGR model [44,45], addressing that Iberian female fetuses favor the development of the viscerae rather than that of the carcass, conversely to male fetuses (i.e.,: females prioritize the growth of vital organs at the expense of the growth of bones and muscles). Evidence indicates that protective strategies to adapt to nutritional scarcity are more evident in the female offspring, similarly to previous data reviewed by Aiken and Ozanne [46]. In the present study, these differences were not found in the metformin-treated group. However, treated piglets (both females and males) demonstrated a higher relative weight of total viscerae than control animals. Therefore, there was a positive effect of the metformin treatment on the offspring developmental competence.

However, it is important to note that the individual assessment of each one of the main viscerae addressed that despite no differences or even a non-significant trend to increase in metformin-treated 
females, the metformin-treated males had lower relative weights of main viscerae (lungs, liver, kidneys, pancreas, spleen and adrenal glands) than the control males. We cannot elucidate if this was a statistical effect of the comparison to total viscera weight (higher in metformin-treated males) due to no differences in the absolute weights of each viscera alone, or if there was a redistribution of the growth of the different viscerae, having in mind that other viscerae were comparatively higher (e.g., intestine). However, these results resemble data from previous studies on the effect of a polyphenol supplementation (i.e., hydroxytyrosol) during pregnancy, where the liver was smaller in treated male offspring and even demonstrated a lower energy content than in their male control counterparts [47-49]. Swine models have proved to be highly translational to human medicine, as previously explained $[5,7,9]$. Thus, these results indicate the need for further specific studies on possible deleterious effects of prenatal therapies regulating fetal homeostasis on male offspring development. Such consideration should be extended to treatments counteracting the effects of maternal PCOS and diabetes during pregnancy.

\section{Material and Methods}

\subsection{Ethics Statement}

The study involved a total of 119 piglets which were born from 15 purebred Iberian sows. All these animals were housed at the INIA facilities, which meet local, national, and European requirements for Scientific Procedure Establishments. The experimental procedures were assessed and approved by the INIA Committee of Ethics in Animal Research and the regional competent authority (report PROEX 353/15) and performed according to the Spanish Policy for Animal Protection RD53/2013, which complies with the European Union Directive 2010/63/UE on the care of animals used for research.

\subsection{Animal Handling and Experimental Procedure}

The experimental procedure was adapted from a previous study evaluating the effect of metformin on fetal development [15]. In brief, the sows were inseminated with cooled semen from a purebred Iberian boar after cycle synchronization with altrenogest (Regumate ${ }^{\circledR}$, MSD, Boxmeer, The Netherlands). All the sows were fed with a standard grain-based food diet (dry matter, $89.8 \%$; crude protein, $15.1 \%$; fat, $2.8 \%$; and metabolizable energy, $3.0 \mathrm{Mcal} / \mathrm{kg}$ ) adjusted to fulfill $100 \%$ of individual daily maintenance requirements during the first 35 days of pregnancy and, in order to impose a nutritional challenge and to induce a higher incidence of IUGR processes as previously described $[10,11]$, reduced to fulfill $50 \%$ of such requirements from Day 35 of pregnancy up to the day of delivery. On the same Day 35 of pregnancy, the sows were distributed according to body weight in an untreated control group (group $\mathrm{C} ; n=6$ ) and a group treated with $850 \mathrm{mg}$ of metformin per animal and day (Dianben ${ }^{\circledR}$; Merck Serono, Madrid, Spain), by individually top-dressing over the morning feed from Day 35 to the day of sampling (group METF; $n=9$ ). All sows were again fed with the control diet from the day of delivery up to weaning.

\subsection{Assessment of Neonatal Features and Early Postnatal Development of Piglets}

At birth, the total number of piglets was recorded for each sow. Sex, weight, and head and body measurements (biparietal diameter, occipito-nasal length, trunk length, and abdominal and thoracic circumferences) were recorded for each piglet. Head measurements were used to calculate the ratio occipito-nasal length/biparietal diameter. Immediately, all living piglets were tagged with earrings for their identification and underwent within-group fostering to equalize the number of animals among dams. Piglets remained with sows in individual pens until weaning at 30 days old.

All the piglets were again weighted and measured at 15 and 30 days old. Weight values were used to determine the ADWG and the FGR; weight gained per day per starting weight) for the time-intervals. At 30 days old, all the piglets were euthanized by stunning and exsanguination in compliance with standard procedures (RD 53/2013) and sampled for determining the effects of maternal metformin treatment on early postnatal body weight and size, adiposity, and body composition. The head was 
immediately separated from the trunk at the atlanto-occipital joint and weighted, all thoracic and abdominal viscerae were removed, and the weight of the carcass and the total viscerae together were recorded. The back-fat depth and the loin diameter were recorded with a measuring tape at the carcass, and the major organs (heart, lungs, liver, intestine, kidney, spleen, pancreas, and adrenal glands) were weighed individually. The following weight ratios were considered: weights of head to body weight and weights of brain, heart, lungs, liver, kidneys, intestine, pancreas, spleen, and adrenal glands relative to both total body weight and total viscera weight.

\subsection{Statistical Analyses}

Data were analyzed using SPSS 22.0 (IBM, NY). T-student tests were used to assess the effects of maternal treatment (control vs. treated) on litter size and distribution of sexes. Effects of treatment (control vs. treated) and sex (female vs. male) on changes over time in weight and measures were assessed by ANOVA for repeated measures with the Green-Houser-Geisser correction when statistically significant while differences in adiposity, loin diameter, and organs weights were assessed by two-way ANOVA. Duncan's post-hoc test was performed to check differences among groups in multiple comparisons. All results were expressed as mean \pm SEM, and statistical significance was accepted from $p<0.05$.

\section{Conclusions}

Overall, the results obtained in the present study show the efficacy of metformin to improve the developmental competence of fetuses from compromised pregnancies. However, there is also evidence of a prominent role of the offspring sex on its response to maternal metformin therapies, which may be even deleterious in the case of male offspring. Such evidence supports the concept of personalized medicine including offspring sex in the case of pregnancies and, specifically, should be taken in account for further preclinical studies and even current clinical application in pregnant women affected by PCOS and diabetes.

Author Contributions: C.G.-C., S.A. and A.G.-B. designed the experiment; C.G.-C., M.V.-G., J.L.P.-P., A.H.-M., T.E., S.A., and A.G.-B. performed the experiment and analyzed the data; C.G.-C., and A.G.-B. wrote the original draft. All authors have read and agreed to the published version of the manuscript.

Funding: The experimental work was supported by funds from the Ministry of Economy and competitiveness (project AGL2015-72198-EXP), co-funded by FEDER. MVG, CGC and AHM are backed by the Spanish Government (MVG: FPU National Program Grant Number FPU014/01285. CGC and AHM: FPI National Program Grant Number BES-2014-070464 and BES-2017-080541, respectively).

Acknowledgments: The authors thank the INIA animal staff for his assistance with animal care and P. Cuesta and I. Cano (Department of Research Support, Universidad Complutense de Madrid) for statistical analyses.

Conflicts of Interest: The authors declare no conflict of interest.

\section{References}

1. Bhutta, Z.A.; Das, J.K.; Rizvi, A.; Gaffey, M.F.; Walker, N.; Horton, S.; Webb, P.; Lartey, A. E Black, REvidence-based interventions for improvement of maternal and child nutrition: What can be done and at what cost? Lancet 2013, 382, 452-477. [CrossRef]

2. Aski, S.K.; Akbari, R.; Hantoushzadeh, S.; Ghotbizadeh, F. A bibliometric analysis of Intrauterine Growth Restriction research. Placenta 2020, 95, 106-120. [CrossRef] [PubMed]

3. Sankaran, S.; Kyle, P.M. Aetiology and pathogenesis of IUGR. Best Pract. Res. Clin. Obstet. Gynaecol. 2009, 23, 765-777. [CrossRef] [PubMed]

4. Ghidini, A. Idiopathic fetal growth restriction: A pathophysiologic approach. Obstet. Gynecol. Surv. 1996, 51, 376-382. [CrossRef] [PubMed]

5. Gonzalez-Bulnes, A.; Astiz, S.; Parraguez, V.H.; Garcia-Contreras, C.; Vazquez-Gomez, M. Empowering translational research in Fetal Growth Restriction: Sheep and swine animal models. Curr. Pharm. Biotechnol. 2016, 17, 848-855. [CrossRef] 
6. Zeitlin, J.; Ancel, P.Y.; Saurel-Cubizolles, M.J.; Papiernik, E. The relationship between intrauterine growth restriction and preterm delivery: An empirical approach using data from a European case-control study. BJOG Int. J. Obstet. Gynaecol. 2000, 107, 750-758. [CrossRef] [PubMed]

7. Gonzalez-Bulnes, A.; Parraguez, V.H.; Berlinguer, F.; Barbero, A.; Garcia-Contreras, C.; Lopez-Tello, J.; Pesantez-Pacheco, J.L.; Martinez-Ros, P. The impact of prenatal environment on postnatal life and performance: Future perspectives for prevention and treatment. Theriogenology 2020, 150, 15-19. [CrossRef]

8. Gonzalez-Bulnes, A.; Ovilo, C.; Lopez-Bote, C.J.; Astiz, S.; Ayuso, M.; Perez-Solana, M.L.; Sanchez-Sanchez, R.; Torres-Rovira, L. Gender-specific early postnatal catch-up growth after intrauterine growth retardation by food restriction in swine with obesity/leptin resistance. Reproduction 2012, 144, 269-278. [CrossRef]

9. Gonzalez-Bulnes, A.; Astiz, S.; Ovilo, C.; Lopez-Bote, C.J.; Torres-Rovira, L.; Barbero, A.; Ayuso, M.; Garcia-Contreras, C.; Vazquez-Gomez, M. Developmental Origins of Health and Disease in swine: Implications for animal production and biomedical research. Theriogenology 2016, 86, 110-119. [CrossRef] [PubMed]

10. Bailey, C.J. Metformin: Historical overview. Diabetologia 2017, 60, 1566-1576. [CrossRef]

11. Lindsay, R.S.; Loeken, M.R. Metformin use in pregnancy: Promises and uncertainties. Diabetologia 2017, 60, 1612-1619. [CrossRef]

12. Hyer, S.; Balani, J.; Shehata, H. Metformin in pregnancy: Mechanisms and clinical applications. Int. J. Mol. Sci. 2018, 19, 1954. [CrossRef] [PubMed]

13. Stumvoll, M.; Nurjhan, N.; Perriello, G.; Dailey, G.; Gerich, J.E. Metabolic effects of metformin in non-insulin-dependent diabetes mellitus. N. Engl. J. Med. 1995, 333, 550-554. [CrossRef]

14. Simmons, D. Safety considerations with pharmacological treatment of gestational diabetes mellitus. Drug Saf. 2015, 38, 65-78. [CrossRef] [PubMed]

15. Garcia-Contreras, C.; Vazquez-Gomez, M.; Pesantez-Pacheco, J.L.; Torres-Rovira, L.; Heras-Molina, A.; Encinas, T.; Astiz, S.; Gonzalez-Bulnes, A. Maternal metformin treatment improves developmental and metabolic traits of IUGR fetuses. Biomolecules 2019, 9, 166. [CrossRef]

16. American Diabetes Association. Management of diabetes in pregnancy: Standards of medical care in diabetes 2019. Diabetes Care 2019, 42, S165-S172. [CrossRef]

17. Douglas, S.L.; Edwards, S.A.; Kyriazakis, I. Are all piglets born lightweight alike? Morphological measurements as predictors of postnatal performance. J. Anim. Sci. 2016, 94, 3510-3518. [CrossRef]

18. Hales, J.; Moustsen, V.A.; Nielsen, M.B.F.; Hansen, C.F. Individual physical characteristics of neonatal piglets affect preweaning survival of piglets born in a noncrated system. J. Anim. Sci. 2013, 91, 4991-5003. [CrossRef]

19. Foxcroft, G.R.; Dixon, W.T.; Novak, S.; Putman, C.T.; Town, S.C.; Vinsky, M.D. The biological basis for prenatal programming of postnatal performance in pigs. J. Anim. Sci. 2006, 84, E105-E112. [CrossRef]

20. Huting, A.M.S.; Sakkas, P.; Wellock, I.; Almond, K.; Kyriazakis, I. Once small always small? To what extent morphometric characteristics and post-weaning starter regime affect pig lifetime growth performance. Porcine Health Manag. 2018, 4, 21. [CrossRef] [PubMed]

21. Vanky, E.; Stridsklev, S.; Heimstad, R.; Romundstad, P.; Skogøy, K.; Kleggetveit, O.; Hjelle, S.; von Brandis, P.; Eikeland, T.; Flo, K.; et al. Metformin versus placebo from first trimester to delivery in polycystic ovary syndrome: A randomized, controlled multicenter study. J. Clin. Endocrinol. Metab. 2010, 95, E448-E455. [CrossRef]

22. Hanem, L.G.E.; Stridsklev, S.; Júlíusson, P.B.; Salvesen, Ø.; Roelants, M.; Carlsen, S.M.; Ødegård, R.; Vanky, E. Metformin use in PCOS pregnancies increases the risk of offspring overweight at 4 years of age: Follow-up of two RCTs. J. Clin. Endocrinol. Metab. 2018, 103, 1612-1621. [CrossRef]

23. Bartholomeusz, H.H.; Courchesne, E.; Karns, C.M. Relationship between head circumference and brain volume in healthy normal toddlers, children, and adults. Neuropediatrics 2002, 33, 239-241. [CrossRef]

24. Charles, B.; Norris, R.; Xiao, X.; Hague, W. Population pharmacokinetics of metformin in late pregnancy. Ther. Drug Monit. 2006, 28, 67-72. [CrossRef] [PubMed]

25. Vanky, E.; Zahlsen, K.; Spigset, O.; Carlsen, S.M. Placental passage of metformin in women with polycystic ovary syndrome. Fertil. Steril. 2005, 83, 1575-1578. [CrossRef]

26. Łabuzek, K.; Suchy, D.; Gabryel, B.; Bielecka, A.; Liber, S.; Okopień, B. Quantification of metformin by the HPLC method in brain regions, cerebrospinal fluid and plasma of rats treated with lipopolysaccharide. Pharmacol. Rep. 2010, 62, 956-965. [CrossRef] 
27. Rehfeldt, C.; Lefaucheur, L.; Block, J.; Stabenow, B.; Pfuhl, R.; Otten, W.; Metges, C.C.; Kalbe, C. Limited and excess protein intake of pregnant gilts differently affects body composition and cellularity of skeletal muscle and subcutaneous adipose tissue of newborn and weanling piglets. Eur. J. Nutr. 2012, 51, 151-165. [CrossRef]

28. Rehfeldt, C.; Stabenow, B.; Pfuhl, R.; Block, J.; Nurnberg, G.; Otten, W.; Metges, C.C.; Kalbe, C. Effects of limited and excess protein intakes of pregnant gilts on carcass quality and cellular properties of skeletal muscle and subcutaneous adipose tissue in fattening pigs. J. Anim. Sci. 2012, 90, 184-196. [CrossRef] [PubMed]

29. Patience, J.F.; Rossoni-Serão, M.C.; Gutiérrez, N.A. A review of feed efficiency in swine: Biology and application. J. Anim. Sci. Biotechnol. 2015, 6, 33. [CrossRef]

30. Witczak, C.A.; Mokelke, E.A.; Boullion, R.; Wenzel, J.; Keisler, D.H.; Sturek, M. Noninvasive measures of body fat percentage in male Yucatan swine. Comp. Med. 2005, 55, 445-451.

31. Dyson, M.C.; Alloosh, M.; Vuchetich, J.P.; Mokelke, E.A.; Sturek, M. Components of metabolic syndrome and coronary artery disease in female Ossabaw swine fed excess atherogenic diet. Comp. Med. 2006, 56, 35-45.

32. Christoffersen, B.O.; Grand, N.; Golozoubova, V.; Svendsen, O.; Raun, K. Gender-associated differences in metabolic syndrome-related parameters in Gottingen Minipigs. Comp. Med. 2007, 57, 493-504.

33. Breier, B.H.; Vickers, M.H.; Ikenasio, B.A.; Chan, K.Y.; Wong, W.P.S. Fetal programming of appetite and obesity. Mol. Cell. Endocrinol. 2001, 185, 73-79. [CrossRef]

34. Hales, C.N.; Ozanne, S.E. The dangerous road of catch-up growth. J. Physiol. 2003, 547, 5-10. [CrossRef]

35. Ross, M.G.; Desai, M. Gestational programming: Population survival effects of drought and famine during pregnancy. Am. J. Physiol. Regul. Integr. Comp. Physiol. 2005, 288, R25-R33. [CrossRef]

36. Ibañez, L.; Ong, K.; Dunger, D.B.; de Zegher, F. Early development of adiposity and insulin resistance after catch-up weight gain in small-forgestational-age children. J. Clin. Endocrinol. Metabol. 2006, 91, 2153-2158. [CrossRef] [PubMed]

37. Barbero, A.; Astiz, S.; Lopez-Bote, C.J.; Perez-Solana, M.L.; Ayuso, M.; Garcia-Real, I.; Gonzalez-Bulnes, A. Maternal malnutrition and offspring sex determine juvenile obesity and metabolic disorders in a swine model of leptin resistance. PLoS ONE 2013, 8, e78424. [CrossRef]

38. Óvilo, C.; Gonzalez-Bulnes, A.; Benítez, R.; Ayuso, M.; Barbero, A.; Perez-Solana, M.L.; Barragán, C.; Astiz, S.; Fernández, A.; López-Bote, C. Prenatal programming in an obese swine model: Sex-related effects of maternal energy restriction on morphology, metabolism and hypothalamic gene expression. Br. J. Nutr. 2014, 111, 735-746. [CrossRef]

39. Astiz, S.; Gonzalez-Bulnes, A.; Astiz, I.; Barbero, A.; Perez-Solana, M.L.; Garcia-Real, I. Advanced onset of puberty after metformin therapy in swine with thrifty genotype. Exp. Physiol. 2014, 99, 1241-1252. [CrossRef]

40. Glueck, C.J.; Goldenberg, N.; Pranikoff, J.; Loftspring, M.; Sieve, L.; Wang, P. Height, weight, and motor-social development during the first 18 months of life in 126 infants born to 109 mothers with polycystic ovary syndrome who conceived on and continued metformin through pregnancy. Hum. Reprod. 2004, 19, 1323-1330. [CrossRef]

41. Ijäs, H.; Vääräsmäki, M.; Saarela, T.; Keravuo, R.; Raudaskoski, T. A follow-up of a randomised study of metformin and insulin in gestational diabetes mellitus: Growth and development of the children at the age of 18 months. BJOG Int. J. Obstet. Gynaecol. 2015, 122, 994-1000. [CrossRef] [PubMed]

42. Rowan, J.A.; Rush, E.C.; Plank, L.D.; Lu, J.; Obolonkin, V.; Coat, S.; Hague, W.M. Metformin in gestational diabetes: The offspring follow-up (MiG TOFU): Body composition and metabolic outcomes at 7-9 years of age. BMJ Open Diabetes Res. Care 2018, 6, e000456. [CrossRef]

43. Rowan, J.A.; Rush, E.C.; Obolonkin, V.; Battin, M.; Wouldes, T.; Hague, W.M. Metformin in gestational diabetes: The offspring follow-up (MiG TOFU): Body composition at 2 years of age. Diabetes Care 2011, 34, 2279-2284. [CrossRef]

44. Gonzalez-Bulnes, A.; Torres-Rovira, L.; Astiz, S.; Ovilo, C.; Sanchez-Sanchez, R.; Gomez-Fidalgo, E.; Perez-Solana, M.; Martin-Lluch, M.; Garcia-Contreras, C.; Vazquez-Gomez, M. Fetal Sex Modulates Developmental Response to Maternal Malnutrition. PLoS ONE 2015, 10, e0142158. [CrossRef]

45. Cogollos, L.; Garcia-Contreras, C.; Vazquez-Gomez, M.; Astiz, S.; Sanchez-Sanchez, R.; Gomez-Fidalgo, E.; Ovilo, C.; Isabel, B.; Gonzalez-Bulnes, A. Effects of fetal genotype and sex on developmental response to maternal malnutrition. Reprod. Fertil. Dev. 2017, 29, 1155-1168. [CrossRef] 
46. Aiken, C.E.; Ozanne, S.E. Sex differences in developmental programming models. Reproduction 2013, 145, R1-R13. [CrossRef]

47. Garcia-Contreras, C.; Vazquez-Gomez, M.; Barbero, A.; Pesantez, J.L.; Zinellu, A.; Berlinguer, F.; Gonzalez-Añover, P.; Gonzalez, J.; Encinas, T.; Torres-Rovira, L.; et al. Polyphenols and IUGR pregnancies: Effects of maternal hydroxytyrosol supplementation on placental gene expression and fetal antioxidant status, DNA-methylation and phenotype. Int. J. Mol. Sci. 2019, 20, 1187. [CrossRef]

48. Vazquez-Gomez, M.; Garcia-Contreras, C.; Torres-Rovira, L.; Pesantez, J.L.; Gonzalez-Añover, P.; Gómez-Fidalgo, E.; Sánchez-Sánchez, R.; Ovilo, C.; Isabel, B.; Astiz, S.; et al. Polyphenols and IUGR pregnancies: Maternal hydroxytyrosol supplementation improves prenatal and early-postnatal growth and metabolism of the offspring. PLoS ONE 2017, 12, e0177593. [CrossRef] [PubMed]

49. Garcia-Contreras, C.; Vázquez-Gómez, M.; Pardo, Z.; Heras-Molina, A.; Encinas, T.; Torres-Rovira, L.; Astiz, S.; Nieto, R.; Óvilo, C.; Gonzalez-Bulnes, A.; et al. Polyphenols and IUGR pregnancies: Effects of maternal hydroxytyrosol supplementation on hepatic fat accretion and energy and fatty acids profile of fetal tissues. Nutrients 2019, 11, 1534. [CrossRef]

Publisher's Note: MDPI stays neutral with regard to jurisdictional claims in published maps and institutional affiliations.

(C) 2020 by the authors. Licensee MDPI, Basel, Switzerland. This article is an open access article distributed under the terms and conditions of the Creative Commons Attribution (CC BY) license (http://creativecommons.org/licenses/by/4.0/). 